\title{
Critical IIIness-Related Corticosteroid Insufficiency (CIRCI): A Narrative Review from a Multispecialty Task Force of the Society of Critical Care Medicine (SCCM) and the European Society of Intensive Care Medicine (ESICM)
}

\author{
Djillali Annane, MD, $\mathrm{PhD}^{1}$; Stephen M. Pastores, MD, FCCM ${ }^{2}$, Wiebke Arlt, MD, DSc, FRCP ; \\ Robert A. Balk, MD, MCCM ${ }^{4}$; Albertus Beishuizen, MD, PhD; ; Josef Briegel, MD, $\mathrm{PhD}^{6}$; \\ Joseph Carcillo, MD, FCCM ${ }^{7}$; Mirjam Christ-Crain, MD, $\mathrm{PhD}^{8}$; Mark S. Cooper, $\mathrm{MD}^{9}$; \\ Paul E. Marik, MD, FCCM ${ }^{10}$; Gianfranco Umberto Meduri, MD ${ }^{11}$; Keith M. Olsen, PharmD, FCCM ${ }^{12}$; \\ Bram Rochwerg, $\mathrm{MD}^{13}$; Sophia C. Rodgers, RN, MSN, ACNP, FCCM ${ }^{14}$; James A. Russell, MD ${ }^{15}$; \\ Greet Van den Berghe, $\mathrm{MD}, \mathrm{PhD}^{16}$
}

${ }^{1}$ General ICU Department, Raymond Poincaré hospital (APHP), Health
Science Centre Simone Veil, Université Versailles SOY-Paris Saclay; Garches, France.

${ }^{2}$ Department of Anesthesiology and Critical Care Medicine, Memorial Sloan Kettering Cancer Center, New York, NY, United States of America.

${ }^{3}$ Institute of Metabolism and Systems Research (IMSR), University of Birmingham \& Centre for Endocrinology, Diabetes and Metabolism (CEDAM), Birmingham Health Partners, Birmingham, United Kingdom.

${ }^{4}$ Division of Pulmonary and Critical Care Medicine, Rush University Medical Center, Chicago, IL, United States of America.

${ }^{5}$ Department of Intensive Care Medicine, Medisch Spectrum Twente, Enschede, Netherlands

${ }^{6}$ Anesthesiology and Critical Care Medicine, Klinik für Anästhesiologie, Klinikum der Universität, Munich, Germany.

${ }^{7}$ Department of Critical Care Medicine and Pediatrics, University of Pittsburgh School of Medicine, Pittsburgh, PA, United States of America.

${ }^{8}$ Department of Endocrinology, Diabetology and Metabolism, Department of Clinical Research, University Hospital Basel, Basel, Switzerland.

${ }^{9}$ Department of Endocrinology, Concord Hospital, University of Sydney, Sydney, New South Wales, Australia.

${ }^{10}$ Division of Pulmonary and Critical Care Medicine, Eastern Virginia Medical School, Norfolk, VA, United States of America.

${ }^{11}$ Division of Pulmonary, Critical Care, and Sleep Medicine, Department of Medicine, Memphis Veterans Affairs Medical Center, Memphis, TN, United States of America.

${ }^{12}$ Dean, College of Pharmacy, University of Arkansas for Medical Sciences, Little Rock, AR, United States of America.

${ }^{13}$ Division of Critical Care, Department of Medicine, McMaster University, Hamilton, Ontario, Canada.

Copyright (C) 2017 by the Society of Critical Care Medicine and the European Society of Intensive Care Medicine. All Rights Reserved.

DOI: 10.1097/CCM.0000000000002724
${ }^{14}$ Clinical Adjunct Faculty, University of New Mexico and Sandoval Regional Medical Center, Albuquerque, NM, United States of America.

${ }^{15}$ Division of Critical Care Medicine, Centre for Heart Lung Innovation, St. Paul's Hospital, University of British Columbia, Vancouver, Canada.

${ }^{16}$ Clinical Division and Laboratory of Intensive Care Medicine, Department of Cellular and Molecular Medicine, KU Leuven University and Hospitals, B-3000 Leuven, Belgium.

Dr. Djillali Annane and Dr. Stephen M. Pastores are co-chairs and co-first authors who have contributed equally to this work.

Dr. Annane has been involved with research relating to this guideline. Dr. Pastores participates in the American College of Physicians: Speaker at ACP Critical Care Update Precourse, the American College of Chest Physicians (CHEST) (faculty speaker at Annual Congress), the American Thoracic Society (ATS): Moderator at Annual Meeting, the European Society of Intensive Care Medicine (EISCM) (co-chair of Corticosteroid Guideline in collaboration with SCCM), and the Korean Society of Critical Care Medicine (co-director and speaker at Multiprofessional Critical Care Board Review Course). He has spoken on the topic of corticosteroid use in critical illness and specifically in sepsis at the International Symposium in Critical and Emergency Medicine in March 2017. Dr. Arlt participates in the Society for Endocrinology UK (Chair of the Clinical Committee, member of Council, member of the Nominations Committee) and the Endocrine Society USA (member, Publication Core Committee). Dr. Briegel participates in the European Society of Intensive Care Medicine, the Deutsche interdisziplinäre Vereinigung Intensivmedizin, and the Deutsche Gesellschaft für Anästhesie und Intensivmedizin, and he has given lectures and talks on hydrocortisone treatment of septic shock. Dr. Cooper participates in a range of specialist societies relating to endocrinology and bone disease. Dr. Meduri disclosed he is a government employee. Dr. Olsen participates in the American College of Clinical Pharmacy (grant review committee), and he represents the American Society of Health-System Pharmacists on the National Quality Forum for Surgery Measures. Dr. Rochwerg disclosed he is a methodologist for ATS, CBS, ESCIM, ASH. The remaining authors have disclosed that they do not have any potential conflicts of interest.

This article is being simultaneously published in Critical Care Medicine and Intensive Care Medicine. ICM DOI: 10.1007/s00134-017-4914-x 
This article is linked to another article entitled "Guidelines for the Diagnosis and Management of Critical IIIness-Related Corticosteroid Insufficiency (CIRCI) in Critically III Patients: Society of Critical Care Medicine (SCCM) and European Society of Intensive Care Medicine (ESICM): 2017" also published in the parallel.

For information regarding this article, E-mail: pastores@mskcc.org

Objective: To provide a narrative review of the latest concepts and understanding of the pathophysiology of critical illness-related corticosteroid insufficiency (CIRCI).

Participants: A multi-specialty task force of international experts in critical care medicine and endocrinology and members of the Society of Critical Care Medicine and the European Society of Intensive Care Medicine.

Data Sources: Medline, Database of Abstracts of Reviews of Effects (DARE), Cochrane Central Register of Controlled Trials (CENTRAL) and the Cochrane Database of Systematic Reviews.

Results: Three major pathophysiologic events were considered to constitute CIRCI: dysregulation of the hypothalamic-pituitaryadrenal (HPA) axis, altered cortisol metabolism, and tissue resistance to glucocorticoids. The dysregulation of the HPA axis is complex, involving multidirectional crosstalk between the $\mathrm{CRH}$ / ACTH pathways, autonomic nervous system, vasopressinergic system, and immune system. Recent studies have demonstrated that plasma clearance of cortisol is markedly reduced during critical illness, explained by suppressed expression and activity of the primary cortisol-metabolizing enzymes in the liver and kidney. Despite the elevated cortisol levels during critical illness, tissue resistance to glucocorticoids is believed to occur due to insufficient glucocorticoid alpha-mediated anti-inflammatory activity.

Conclusions: Novel insights into the pathophysiology of $\mathrm{CIRCI}$ add to the limitations of the current diagnostic tools to identify at-risk patients and may also impact how corticosteroids are used in patients with CIRCI. (Crit Care Med 2017; 45:2089-2098)

Key Words: Corticosteroid insufficiency; critical illness; sepsis; glucocorticoids; glucocorticoid receptor

\section{INTRODUCTION}

In 2008 an international multidisciplinary task force convened by the Society of Critical Care Medicine (SCCM) coined the term critical illness-related corticosteroid insufficiency (CIRCI) to describe impairment of the hypothalamic-pituitary-adrenal (HPA) axis during critical illness (1). CIRCI was defined as inadequate cellular corticosteroid activity for the severity of the patient's critical illness, manifested by insufficient glucocorticoid-glucocorticoid receptor-mediated down regulation of pro-inflammatory transcription factors. CIRCI is thought to occur in several acute conditions including sepsis and septic shock, severe community-acquired pneumonia, acute respiratory distress syndrome (ARDS), cardiac arrest, head injury, trauma, burns, and post-major surgery. This narrative review, performed by a multi-specialty task force of international experts and members of the SCCM and the European Society of Intensive Care Medicine (ESICM), focuses on the latest concepts and understanding of the pathophysiology of CIRCI during critical illness.

\section{Hypotalamic Pituitary Adrenal Axis and the Physiological Response to Stress}

Systemic inflammation-a central component of the innate immune system-is a highly organized response to infectious and non-infectious threats to homeostasis that consists of at least three major domains (1): the stress system mediated by the HPA axis and the locus ceruleus-norepinephrine/sympathetic nervous system (2), the acute-phase reaction (3), and the target (vital organs) tissue defense response $(2,3)$. Whereas appropriately regulated inflammation-tailored to stimulus and time (4)-is beneficial, excessive or persistent systemic inflammation incites tissue destruction and disease progression (5).

Overwhelming systemic inflammation that characterizes critical illness is partly driven by an imbalance between hyperactivated inflammatory pathways such as the classical nuclear factor-kappa B (NF-kB) signaling system (6) and the less activated or dysregulated HPA-axis response (7). The activated glucocorticoid-glucocorticoid receptor-alpha (GC-GR $\alpha$ ) complex plays a fundamental role in the maintenance of both resting and stress-related homeostasis and influences the physiologic adaptive reaction of the organism against stressors (2). The activated GC-GR $\alpha$ complex exerts its activity at the cytoplasmic level and on nuclear deoxyribonucleic acid (nDNA) and mitochondrial DNA (mtDNA) (8) affecting thousands of genes involved in response to stress and non-stress states (9). Individual genetic variants of the glucocorticoid receptor may also affect both the basic cellular phenotypes, i.e., GR expression levels and the overall HPA axis stress response through either an altered GC response or sensitivity (10).

\section{Cortisol Synthesis}

The adrenal glands produce glucocorticoids (cortisol), mineralocorticoids (aldosterone), and adrenal androgens (dehydroepiandrosterone, DHEA) using cholesterol as a substrate, and upon stimulation by adrenocorticotropic hormone (ACTH), also known as corticotropin (Figure 1). ACTH is a short half-life, fast-acting 39-amino acid peptide produced from the cleavage of a large precursor, proopiomelanocortin. ACTH stimulatory activity is regulated by corticotropin releasing hormone $(\mathrm{CRH})$ and to a lesser extent by arginine vasopressin (AVP), both acting synergistically. Steroidogenic cholesterol is stored in lipid droplets as cholesteryl esters. Adrenal mitochondria play a critical role in adrenocortical cell steroidogenesis, converting intracellular cholesterol to cortisol. The final steps in glucocorticoid biosynthesis are catalyzed by two closely related mitochondrial P450-type enzymes: CYP11B1 and CYP11B2 (11). Cortisol is the major endogenous glucocorticoid secreted by the human adrenal cortex. Cortisol is released in a circadian rhythm: cortisol production is at its peak in the early hours of the morning and then secretion gradually declines over the course of the day. 


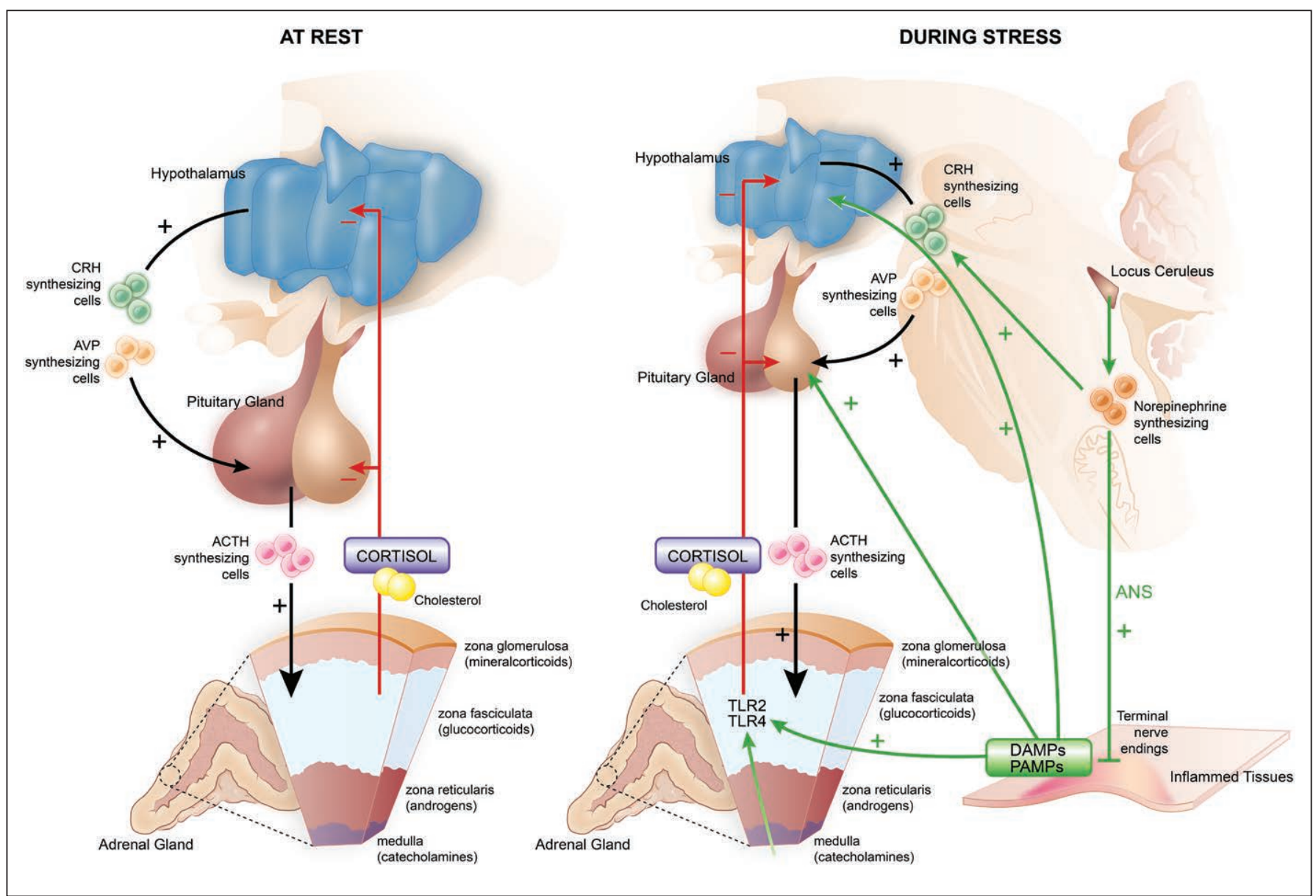

Figure 1. Glucocorticoid synthesis at rest and during stress. At rest, glucocorticoids (e.g., cortisol) are produced from the zona fasciculata of the adrenal cortex upon stimulation by adrenocorticotropic hormone (ACTH) released in the blood from the anterior pituitary gland. Both corticotropin-releasing hormone $(\mathrm{CRH})$ and arginine vasopressin (AVP), synthesized in the hypothalamus, contribute to the synthesis and release of ACTH by pituitary cells. During stress, the synthesis of ACTH is additionally stimulated by norepinephrine, mainly produced in the locus ceruleus. At the level of inflamed tissues, terminal nerve endings of afferent fibers of the autonomic nervous system (ANS) have receptors for damage-associated molecular patterns (DAMPs) and pathogen-associated molecular patterns (PAMPs) allowing them to sense the threat and activate the noradrenergic/CRH system. These DAMPs and PAMPs can also directly stimulate adrenal cortex cells that possess Toll-like receptors (TLR), resulting in ACTH-independent cortisol synthesis. In addition, paracrine routes allow the medulla to also stimulate glucocorticoid synthesis independently of ACTH.

Cortisol itself exerts inhibitory control on the pituitary and hypothalamus to regulate its release. The estimated daily production rate of cortisol is $27-37.5 \mu \mathrm{mol} /$ day (5-7 $\mathrm{mg} / \mathrm{m}^{2} /$ day) (12). There is limited adrenal storage of cortisol. Under the stress of critical illness, the regulation of cortisol production becomes much more complex involving multidirectional crosstalk between the CRH/ ACTH pathways, autonomic nervous system, vasopressinergic system, and immune system (Figure 1). Acute stress induces rapid release of ACTH via CRH and AVP and loss of the circadian rhythm of cortisol secretion. In critically ill patients, increased cortisol levels do not appear to be due to increased adrenocortical sensitivity to ACTH (13). The dissociation of cortisol from ACTH could be due to direct production of cortisol from the adrenal glands or to reduced metabolism of cortisol and thus an increased systemic half-life. Cortisol production rates in critically ill patients were recently shown to be either unaltered or only slightly increased compared with matched control subjects tested in an ICU environment $(14,15)$.

\section{Cortisol Transport and Metabolism}

In plasma, a large proportion (80\%-90\%) of circulating cortisol is bound with high affinity to corticosteroid-binding globulin (CBG), with smaller $(10 \%-15 \%)$ proportions bound with low affinity to albumin or present in the 'free' unbound form. The binding capacity of CBG is typically saturated at cortisol concentrations of $22-25 \mu \mathrm{g} / \mathrm{dL}$. When cortisol levels are higher than $25 \mu \mathrm{g} / \mathrm{dL}$, there is an increased proportion of albuminbound and free cortisol, whereas the amount of CBG-bound cortisol remains the same. Albumin and CBG are negative acute phase reactants and rapidly decrease in critical illness in proportion to the severity of illness (16). In septic patients, reduction in CBG levels correlates with plasma interleukin-6 (IL-6) levels (17).

Cortisol is metabolized primarily in the liver and the kidneys. In the liver, the most important enzymes catalyzing the initial steps in cortisol metabolism are the $5 \alpha / \beta$-reductases, whereas in the kidney, cortisol is broken down to the inactive metabolite cortisone by the $11 \beta$-hydroxysteroid dehydrogenase (11ß-HSD) type 2 enzyme (14). Some cortisol can 
be regenerated from cortisone in extra-adrenal tissues (liver, adipose tissue, skeletal muscles) through the activity of the $11 \beta$-HSD1 enzyme. The adverse metabolic complications associated with corticosteroid excess involve the key metabolic tissues (liver, adipose tissue, and skeletal muscle) which have comparatively high $11 \beta-\mathrm{HSD} 1$ activity.

In stressed conditions, the increase in cortisol level can lead to an increase in the free fraction in the circulation. Additionally, plasma CBG levels can decrease through reduced liver synthesis and increased peripheral cleavage by activated neutrophil elastases. These effects act to increase the amount of cortisol delivered to the tissues. During stress the metabolism of cortisol can also undergo significant changes. The expression and activity of 5-reductases within the liver and probably other tissues is decreased in response to inflammation (14). Renal $11 \beta-H S D 2$ is also decreased in response to inflammation, while the expression of $11 \beta$ HSD1 is increased in some tissues (18). Up regulation of $11 \beta$-HSD 1 activity is modulated by inflammatory cytokines (tumor necrosis factor-alpha [TNF- $\alpha$ ], IL-1 $\beta$ ). These effects would be expected to increase the cortisol action at the level of specific tissues and also increase the half-life of circulating cortisol $(18,19)$.

\section{Cellular Cortisol Signaling}

Cortisol is a lipophilic hormone that enters cells passively and binds to specific cytoplasmic receptors, or to membrane sites. There are two types of glucocorticoid receptors (GR). The type 1 receptor is more commonly referred to as the mineralocorticoid receptor (MR) and the type 2 receptor as the classical GR. Both the GR and the MR can bind aldosterone and cortisol. In many tissues the ability of the MR to bind cortisol is reduced by the expression of the $11 \beta-\mathrm{HSD} 2$ enzyme and the conversion to inactive cortisone. The MR has a higher affinity for cortisol and aldosterone than the GR and is thought to be important for signaling at low corticosteroid concentrations. Although the MR is involved in some inflammatory responses, the classic GR is thought to be more important in mediating the glucocorticoid responses to stress and inflammation. Several transcriptional and translational isoforms of the GR exist, which appear to vary in their tissue distribution and gene-specific effects. Our current understanding of the GR's mechanism of action is mainly obtained from research on the almost ubiquitous and most abundant full-length GR $\alpha$ isoform (20).

In the absence of glucocorticoids, the GR is primarily present in the cytoplasm as part of a multiprotein complex with chaperone proteins, heat shock proteins, and immunophilins (FKBP51 and FKBP52). Upon binding of glucocorticoid, the GR undergoes a conformational change, dissociates from the chaperone proteins, and enters the nucleus and mitochondria, where it binds to positive (transactivation) or negative (cis-repression) specific DNA regions termed glucocorticoid responsive elements (GRE) to regulate transcription and translation of target genes in a cell- and gene-specific manner $(21,22)$ (Figure 2). The glucocorticoid receptor can inhibit the expression of pro-inflammatory genes independently of DNA binding by physically interacting (via tethering) with the transcription factor $\mathrm{p} 65$, a subunit of nuclear factor $\mathrm{\kappa B}$, an effect referred to as transrepression. This interaction inhibits p65-p50 heterodimer translocation into and action at the nucleus (21). Alternatively, in transactivation, GR binding to GRE in the promoter regions of target genes is followed by recruitment of other proteins such as co-activators, resulting in increased pro-inflammatory gene transcription.

Glucocorticoids can induce some anti-inflammatory effects through non-genomic effects (Figure 2). Specifically, membrane-bound GR can activate kinase pathways within minutes. The activation of the mitogen-activated protein kinase (MAPK) pathway results in the inhibition of cytosolic phospholipase A2 $\alpha$, whereas activated phosphatidylinositol 3-kinase leads to the induction of endothelial nitric oxide synthetase (eNOS) and the subsequent production of nitric oxide (21). Endothelial GR is a critical regulator of NO synthesis in sepsis (23). In experimental lipopolysaccharide (LPS) models, tissue-specific deletion of the endothelial GR results in prolonged activation of NF-kB with increased expression of eNOS and inducible nitric oxide synthase (iNOS), TNF- $\alpha$, and IL-6 (23). Importantly, the presence of endothelial GR is required for dexamethasone to rescue the animals from lipopolysaccharide (LPS)-induced morbidity and mortality (24). Glucocorticoids may also impair T-cell receptor signaling through non-genomic inhibition of FYN oncogene-related kinase and lymphocyte-specific protein tyrosine kinase by the glucocorticoid receptor (21).

In addition to the wild-type glucocorticoid receptor GR $\alpha$, two splice variants involving the hormone-binding domain exist, namely GR $\beta$ and GR-P (also known as GRס) $(25,26)$. GR $\beta$ differs from the GR $\alpha$ at the $C$ terminus, resulting in a lack of binding to GCs, constitutive localization in the nucleus, and an inability to transactivate a GC-responsive reporter gene. However, it acts as a dominant-negative inhibitor of GR $\alpha$ genomic transactivation and transrepression when co-expressed with GR $\alpha$; imbalance between GR- $\alpha$ and GR- $\beta$ expression is associated with GC insensitivity (26). Cell-specific glucocorticoid responsiveness also involves differential expression of co-receptor proteins functioning as co-activators and co-repressors of transcription. Also, differences in chromatin structure and DNA methylation status of GR-target genes determine cell specific cortisol effects (27). Besides classical genomic and rapid GC-induced non-genomic ligand-dependent steroid receptor actions and crosstalk, there is increasing evidence that the unliganded GR can modulate cell signaling in the absence of glucocorticoids, adding another level of complexity (20).

In sepsis, glucocorticoids may decrease HLA-DR expression on circulating monocytes at a transcriptional level via a decrease in the class II transactivator A transcription (28). Another study found that hydrocortisone treatment reduced the levels of anti-inflammatory cytokines such as soluble TNF 


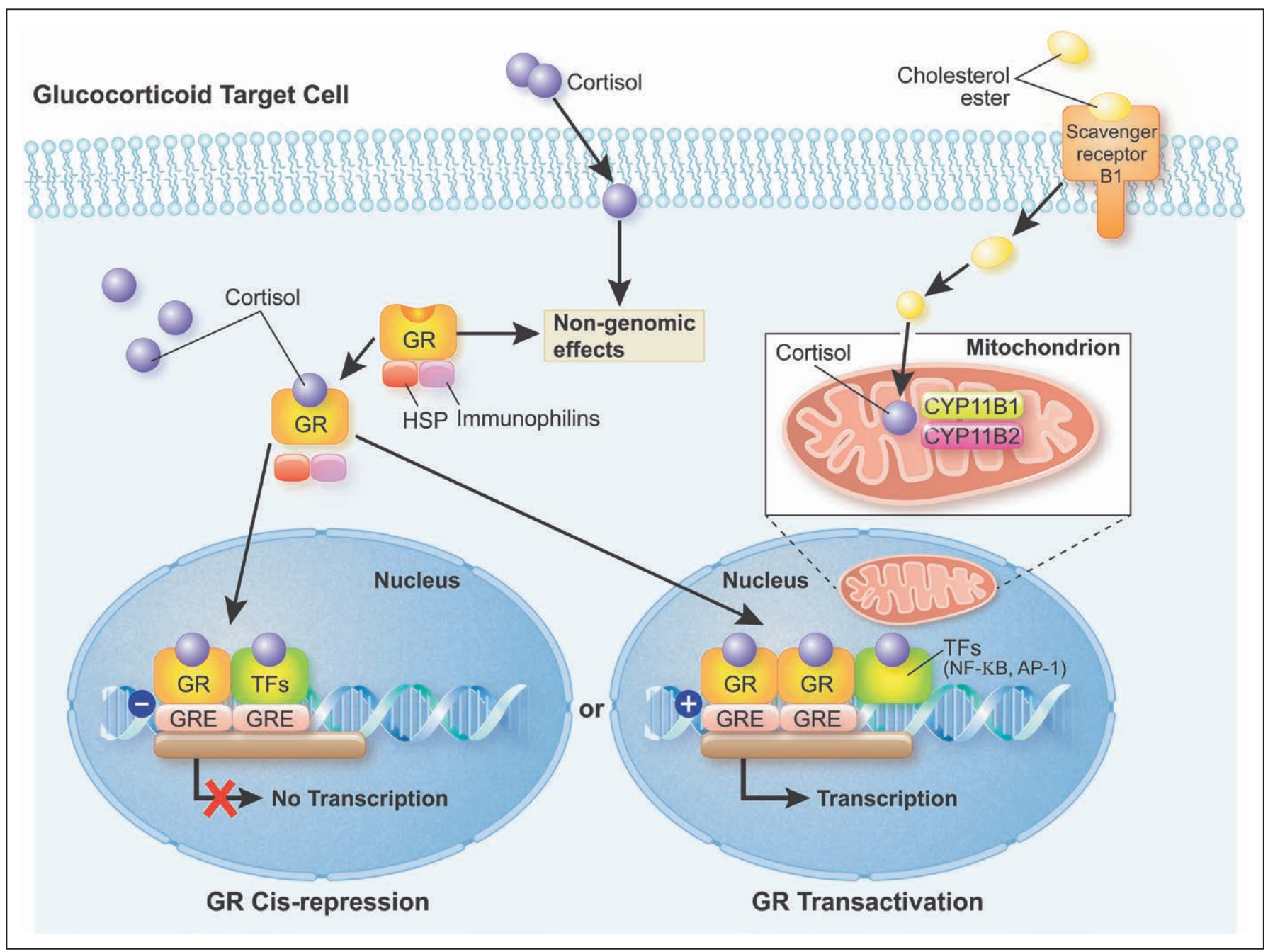

Figure 2. Glucocorticoid synthesis and signalling. Glucocorticoids (e.g., cortisol) are synthesized from cholesterol in the mitochondria by two P450type enzymes, CYP11B1 and CYPB11B2, and may exert genomic and non-genomic effects. Glucocorticoids diffuse through cell membranes and bind with glucocorticoid receptors (GR, classic GR and MR, mineralocorticoid receptor). Glucocorticoid receptors reside in the cytoplasm in a multiprotein complex with chaperone proteins, heat shock proteins, and immunophilins. The classic GR (specifically GR- $\alpha$ ) is the major receptor involved in mediating the glucocorticoid responses to stress and inflammation. Upon binding of cortisol, the GR undergoes a conformational change that allows it to dissociate from the chaperone proteins and translocate into the nucleus and the mitochondria, where it binds to glucocorticoid response elements (GRE) to activate (transactivation) or repress (cis-repression) pro-inflammatory gene expression of various transcription factors (TFs) such as nuclear factor-kappa B (NF-KB) and activator protein-1 (AP-1).

receptors I and II and IL-10, and has only limited effects on HLA-DR expression by circulating monocytes (29).

\section{Dysfunction of the HPA Axis During Critical Illness}

Many of the responses normally considered adaptive may be inadequate or counterproductive during severe stress states. Depending on the population of patients studied and the diagnostic criteria, dysfunction of the HPA axis has been estimated to occur at rates from $10 \%-20 \%$ in critically ill medical patients to as high as $60 \%$ in patients with septic shock (1).

Evidence from the sepsis (30-34), ARDS (7, 35, 36), and trauma $(37,38)$ literature suggests that degree of elevation in inflammatory cytokines (e.g., TNF, IL-1 $\beta$, IL-6) on ICU admission and during ICU stay correlates with disease severity and hospital mortality, and that persistent elevation of cytokines at hospital discharge is associated with adverse long-term outcomes (39).

\section{Cytokine-Induced Activation of the HPA Axis}

Inflammatory cytokines including TNF, IL-1 and IL-6 have been shown to activate the HPA axis, especially during sepsis. However, these cytokines do not exert an equivalent effect on CRH release. IL-1 injection is associated with a strong and sustained activation of the HPA axis, while IL-6 and TNF induce weak and transient hypothalamic responses, and IL-2 and interferon-alpha have no effect (40). The route of cytokine administration (intravenous or intraperitoneal) also influences their stimulatory effects on the hypothalamus (41).

It is also likely that cytokines can exert a direct, ACTHindependent effect on adrenal cortisol synthesis (42). The presence of TNF and of its receptors within the adrenal glands suggests that this cytokine plays a role in adrenal function, even though experiments found variably stimulatory $(43,44)$ or inhibitory $(45,46)$ effects of TNF on steroidogenesis. Likewise, 
IL-1 and its receptor are also produced in the adrenal glands and contribute to steroidogenesis at least partly by regulating prostaglandin pathways (47). Toll-like receptors (TLR), mainly TLR2 and TLR4, are expressed in the adrenal glands and play a critical role in the local immune-endocrine crosstalk in LPS-challenged rodents $(48,49)$. Further experiments using genetically manipulated mice suggest that immune cells and not steroid-producing cells are key regulators of the immuneendocrine local interaction (49).

\section{Impairment of Adrenal Cortisol Synthesis}

Damage to Neuroendocrine Cells. Sepsis is infrequently associated with necrosis or hemorrhage of components of the HPA axis. As a result of the limited venous drainage of the adrenal glands, sepsis-associated massive increase in arterial blood flow to these glands results in enlarged glands (50). Adrenal necrosis and hemorrhage as a consequence of sepsis has been known for more than a century (51). Predisposing factors of the so-called Waterhouse-Friderichsen syndrome include renal failure, shock, disseminated intravascular coagulation, and treatment with anticoagulants or tyrosine kinase inhibitors. Ischemic lesions and hemorrhage have also been described within the hypothalamus or pituitary gland at postmortem examination in septic shock (52).

Altered CRH/ACTH Synthesis. Hypothalamic/pituitary gland stimulation by cytokines, particularly IL-1, induces a biphasic response with initial proportional increase followed by progressive decline in anterior pituitary ACTH concentrations $(53,54)$. In animal models (55) and in humans (56), sepsis is associated with marked overexpression of iNOS in hypothalamic nuclei that is partly triggered by TNF and IL-1. Subsequent abundant release of $\mathrm{NO}$ may cause apoptosis of neurons and glial cells in the neighborhood. Sepsis is also associated with decreased ACTH synthesis, though its secretagogues CRH and vasopressin remained unaltered (57). Thus, the suppression in ACTH synthesis following sepsis may be mediated by NO (58). In addition, feedback inhibition exerted by elevated circulating free cortisol, driven by ACTH-independent mechanisms and suppressed cortisol breakdown, can suppress ACTH $(14,15,59)$.

ACTH synthesis can also be inhibited by several therapeutic agents such as glucocorticoids, opioid analgesics, azole antifungals (e.g., ketoconazole) or psychoactive drugs (60). In animals, depending on the dose, timing and duration, opioids have been shown to variably stimulate or inhibit the CRH/ ACTH axis, whereas in humans they predominantly inhibit it (61). Both endogenous and exogenous glucocorticoids exert negative feedback control on the HPA axis by suppressing hypothalamic CRH production and pituitary ACTH secretion. This suppression can render the adrenal glands unable to generate sufficient cortisol after glucocorticoid treatment is stopped. Abrupt cessation, or too rapid withdrawal, of glucocorticoid treatment may then cause symptoms of adrenal insufficiency $(1,21)$. In non-ICU patients, even after a few days of glucocorticoid treatment, removal without tapering leads to adrenal suppression (measured with corticotropin test) in $45 \%$ of patients with gradual recovery over a period of 14 days (62). Ample experimental and clinical evidence (29-36) shows that premature discontinuation of glucocorticoids in patients with severe sepsis or ARDS frequently $(25 \%-40 \%)$ leads to rebound systemic inflammation and clinical relapse (hemodynamic deterioration, recrudescence of ARDS, or worsening multiple organ dysfunction). Experimental animal sepsis models have demonstrated an early marked increase in ACTH levels that returns to baseline values at around 72 hours (63). Compared with healthy volunteers, clinical studies have found ACTH levels to be significantly lower in critically ill septic patients $(14,64,65)$. Decreased ACTH levels are observed during the first week of ICU stay $(14,15)$. In septic patients, reduction in inflammatory cytokine levels correlates with increases in ACTH levels by ICU day 7 to day 10 (21). Altered ACTH synthesis in response to metyrapone was observed in roughly half of patients with septic shock and very occasionally in critically ill patients without sepsis (64). The reduced ACTH secretion could also be secondary to changes in the feedback regulation of the HPA axis, as described below. Prolonged reduction of ACTH signaling within adrenocortical cells may result in adrenal atrophy (59).

Altered Adrenal Steroidogenesis. The adrenal storage of cortisol is very limited. Thus, an adequate adrenal response to stress relies almost entirely on cortisol synthesis. The HPA axis response to sepsis has not been well defined. There is some evidence that cortisol production rate is somewhat increased in critically ill patients with systemic inflammatory response syndrome (14). As noted earlier, about half of patients with septic shock have decreased cortisol synthesis as assessed by response to the metyrapone test (64). Following administration of metyrapone, $60 \%$ of patients with septic shock had 11-deoxycortisol concentrations of less than $7 \mu \mathrm{g} / \mathrm{dL}$, suggesting decreased corticosteroid synthesis by adrenocortical cells. The alteration may occur at various steps in the cortisol synthesis chain. Histological examination of the adrenal cortex of both animals and humans with sepsis found marked depletion in lipid droplets, suggesting deficiency in esterified cholesterol storage (66). This sepsis-induced loss in lipid droplets is likely mediated by annexin A1 and formyl peptide receptors (67). During critical illness, both increased plasma ACTH concentrations and depletion in adrenal cholesterol stores upregulate adrenal scavenger receptor class B type 1 (SR-B1), an HDL receptor, which captures esterified cholesterol from blood (68). SR-B1-mediated cholesterol uptake is considered as an essential protective mechanism against endotoxin (69). In one study, sepsis induced-deficiency in SR-B1 expression by the adrenal cortex was associated with increased mortality (70).

A number of environmental factors may also have substantial inhibitory effects on adrenal steroidogenesis. Steroidogenesis may be inhibited at various enzymatic steps by drugs, including P-450 aromatase, hydroxysteroid-dehydrogenase, or mitochondrial cytochrome P-450-dependent enzymes (60). In critically ill patients undergoing rapid sequence intubation, the use of etomidate, a drug known to inhibit the last enzymatic 
step in cortisol synthesis, increased the risk of adrenal insufficiency between 4 to 6 hours (OR 19.98; 95\% CI 3.95 to 101.11) and at 12 hours (OR 2.37; 95\% CI 1.61 to 3.47 ) post-dosing (71). This effect was associated with worsening in organ dysfunction but the ultimate effect on mortality remains unclear. Analgesia and sedation may also affect HPA-axis response in critical illness. Opioids administered to opioid-naive subjects rapidly and profoundly inhibit both stress-related cortisol production and cortisol response to cosyntropin stimulation, while chronic opioid consumers occasionally manifest adrenal crises, phenomena apparently induced by inhibition of the HPA axis at multiple sites (72). Benzodiazepines, similarly, quickly induce diminished cortisol formation by inhibiting activity at multiple central and peripheral sites in the HPA axis, including that of adrenal microsomal 17- and 21-hydroxylase activity as well as 11- $\beta$-hydroxylase activity in adrenal mitochondria (73) Finally, experimental studies have shown that inflammatory mediators such as corticostatins may bind to ACTH receptors in the adrenal cortex, thus preventing ACTH stimulation of cortisol synthesis (74).

Altered Extra-Adrenal Corticosteroid Metabolism. There is evidence for altered activity of corticosteroid-metabolizing enzymes during inflammation and critical illness. These changes can influence local tissue action of glucocorticoids and impact the activity of the HPA axis. Even though daytime cortisol production rate is increased in sepsis, the absolute increase appears much less than previously thought. Also, nocturnal cortisol production is not different from that in healthy subjects (15) despite the level of cortisol in the circulation increasing. Several studies have also demonstrated that the half-life of cortisol is dramatically increased during severe sepsis and other critical illnesses $(14,15)$. All of these findings suggest that reduced cortisol breakdown may be a major feature of sepsis. Experiments involving a range of in vivo and ex vivo techniques showed that the expression and activity of the glucocorticoidinactivating 5-reductase enzymes are decreased (14). Additional studies demonstrate that reduced metabolism of cortisol impacted the pulsatile release of ACTH (15). Post-mortem studies of patients who died after prolonged sepsis demonstrate reduced adrenal cortical size and changes in adrenal morphology in keeping with reduced exposure of the adrenal cortex to ACTH (59). These results suggest that some of the long-term changes in the HPA axis associated with critical illness are due to altered metabolism of cortisol that leads to reduced capacity for future cortisol secretion in response to stress. Other studies examining endocrine testing during prolonged critical illness may need re-evaluation in the light of this altered physiology.

\section{Tissue Resistance to Glucocorticoids}

Besides the availability of cortisol, the sensitivity of target tissues to cortisol is important in the regulation of cortisol bioactivity. Intracellular glucocorticoid resistance refers to inadequate glucocorticoid receptor alpha (GR- $\alpha$ ) activity despite seemingly adequate plasma cortisol concentrations (75). Since the GR- $\alpha$ ultimately controls GC-mediated activity, any condition that affects its binding affinity, concentration, transport to the nucleus, and interactions with GRE (nuclear and mitochondrial) or other relevant transcription factors (NF-kB, AP-1) and co-regulators can eventually affect the response of cells to glucocorticoids (75). Tissue resistance to glucocorticoids has been implicated in chronic inflammatory diseases such as chronic obstructive pulmonary disease, severe asthma, systemic lupus erythematosus, ulcerative colitis, and rheumatoid arthritis (76). Glucocorticoid resistance is also recognized as a potential complication of critical illness, with most of the evidence originating from the sepsis and ARDS clinical and experimental literature (75-81). Critical illness is associated with reduced GR- $\alpha$ density and transcription (7, $25,82,83$ ) and increased GR- $\beta$ (dominant negative activity on GR-induced transcription) $(80,83,84)$. These changes are considered maladaptive, since GR- $\alpha$ up regulation was shown to augment the effects of available glucocorticoids (81). Clinical studies in patients with septic shock $(79,80)$ and ARDS (7) have provided evidence of an association between the degree of intracellular glucocorticoid resistance, disease severity, and mortality.

Ex vivo experiments suggest that, in ARDS, insufficient GC-GR $\alpha$-mediated activity is a central mechanism for the upregulation of NF-kB activity $(7,81)$. Plasma samples from patients with declining inflammatory cytokine levels (and thus a state of regulated systemic inflammation) over time elicited a progressive increase in GC-GR $\alpha$-mediated activity (GR $\alpha$ binding to NF-kB and to glucocorticoid response elements on DNA, stimulation of inhibitory protein I $\mathrm{B} B \alpha$ and of IL-10 transcription), and a corresponding reduction in NF-kB nuclear binding, and transcription of TNF- $\alpha$ and IL-1 $\beta$. In contrast, plasma samples from patients with sustained elevation in inflammatory cytokine levels elicited only modest longitudinal increases in GC-GR $\alpha$-mediated activity and a progressive increase in NF-kB nuclear binding over time that was most striking in non-survivors (suggesting a dysregulated, NF-kBdriven response). Analysis of lung tissue obtained by open lung biopsy demonstrated that the degree of NF-kB and GR $\alpha$ activation was associated with histological progression of ARDS, with positive correlation between severity of fibroproliferation and nuclear uptake of NF-kB and a lower ratio of GR $\alpha$ : NF-kB nuclear uptake (7). Similarly, in experimental ARDS, lung tissue demonstrated reduced GR $\alpha$ expression and increased GR $\beta$ expression, leading to decreased GR $\alpha$ nuclear translocation (84).

The effect of exogenous glucocorticoids on intracellular glucocorticoid resistance was studied in both circulating and tissue cells. In experimental ARDS, low-dose glucocorticoid treatment compared with placebo restored GR $\alpha$ number and function with resolution of pulmonary inflammation (7). Similarly, in an ex-vivo ARDS study, prolonged methylprednisolone treatment-contrary to placebo-was associated with upregulation in GR $\alpha$ number, GR $\alpha$ binding to NF-kB, GR $\alpha$ nuclear translocation leading to reduction in NF-kB DNAbinding and transcription of inflammatory cytokines (81). 
Treatment with glucocorticoids led to a change in the longitudinal direction of systemic inflammation from dysregulated (NF-kB-driven response, maladaptive lung repair) to regulated (GR $\alpha$-driven response, adaptive lung repair), with significant reduction in indices of alveolar-capillary membrane permeability and markers of inflammation, hemostasis, and tissue repair.

Sepsis is characterized by decreased GR- $\alpha$ in circulating cells, in liver and muscle $(25,82,83)$. In addition, there is decreased GR- $\alpha$ transcription in circulating cells and lymph node/spleen, in liver and kidney, and lung tissue (77). Sepsis is also characterized by an increased expression of the GR isoform GR- $\beta$ in circulating cells, resulting in an imbalance between GR $\alpha$ and GR $\beta(80,83)$. All these changes are likely to contribute to corticosteroid resistance at a tissue level. Tissue resistance to corticosteroid is highly variable and correlates with severity of illness and mortality (85).

\section{SUMMARY}

Three major pathophysiologic events account for CIRCI: dysregulation of the HPA axis, altered cortisol metabolism, and tissue resistance to corticosteroids (Table 1). During critical illness, the regulation of cortisol production becomes much more complex, involving multidirectional crosstalk between the CRH/ACTH pathways, autonomic nervous system, vasopressinergic system, and immune system. Recent studies have shown that plasma clearance of cortisol is markedly reduced during critical illness, explained by suppressed expression and activity of the main cortisol-metabolizing enzymes in liver and kidney. Additionally, cortisol production rate in critically ill patients is only moderately increased to less than double that of matched healthy subjects. In the face of low plasma ACTH concentrations, these data suggest that other factors drive hypercortisolism during critical illness, which may suppress ACTH by feedback inhibition. Finally, intracellular glucocorticoid resistance from insufficient GR- $\alpha$-mediated anti-inflammatory activity (reduced GR- $\alpha$ density and transcription) and an increased expression of GR- $\beta$ in circulating cells resulting in an imbalance between GR $\alpha$ and GR $\beta$ can be found in critically ill patients despite seemingly adequate circulating cortisol levels. These new insights add to the limitations of the current diagnostic tools to identify patients at risk for CIRCI and may also impact how corticosteroids are used in patients with CIRCI.

\section{TABLE 1. Main Mechanisms of Critical IIIness-Related Corticosteroid Insufficiency}

\begin{tabular}{|c|c|c|}
\hline General defect & Main mechanisms & Key factors \\
\hline \multicolumn{3}{|l|}{$\begin{array}{l}\text { Decrease in cortisol } \\
\text { production }\end{array}$} \\
\hline \multirow[t]{5}{*}{$\begin{array}{l}\text { Altered adrenal synthesis of } \\
\text { cortisol }\end{array}$} & Necrosis/hemorrhage & $\begin{array}{l}\text { Acute kidney failure; hypo-coagulation; disseminated intravascular } \\
\text { coagulation; cardiovascular collapse; tyrosine kinase inhibitors }\end{array}$ \\
\hline & $\begin{array}{l}\text { Decreased availability of } \\
\text { esterified cholesterol }\end{array}$ & $\begin{array}{l}\text { Depletion in adrenal storage regulated by annexin A1-formyl } \\
\text { peptide receptors } \\
\text { Down regulated scavenger receptor-B1 }\end{array}$ \\
\hline & Inhibition of steroidogenesis & Immune cells/Toll-like receptors/cytokines \\
\hline & & Drugs (e.g., sedatives, corticosteroids) \\
\hline & & ACTH-like molecules (e.g., corticostatins) \\
\hline \multirow{3}{*}{$\begin{array}{l}\text { Altered synthesis of } \mathrm{CRH} / \\
\text { ACTH }\end{array}$} & & $\begin{array}{l}\text { Increased negative feedback from circulating cortisol following } \\
\text { up regulation of ACTH-independent mechanisms of cortisol } \\
\text { synthesis }\end{array}$ \\
\hline & & Drugs (e.g., sedatives, anti-infective, psychoactive agents) \\
\hline & & Inappropriate cessation of glucocorticoid treatment \\
\hline \multirow[t]{2}{*}{$\begin{array}{l}\text { Alteration of cortisol } \\
\text { metabolism }\end{array}$} & Decreased cortisol transport & $\begin{array}{l}\text { Down regulation of liver synthesis of cortisol-binding globulins and } \\
\text { albumin }\end{array}$ \\
\hline & Reduced cortisol breakdown & $\begin{array}{l}\text { Decreased expression and activity of the glucocorticoid-inactivat- } \\
\text { ing 5-reductase enzymes in the liver with putative role of bile } \\
\text { acids; Decreased expression and activity of the hydroxysteroid } \\
\text { dehydrogenase in the kidney }\end{array}$ \\
\hline
\end{tabular}




\section{ACKNOWLEDGMENTS}

We acknowledge the assistance of Susan Weil-Kazzaz, CMI, Manager, Design \& Creative Services, Department of Communications, Memorial Sloan Kettering Cancer Center, New York, NY for preparation of the figures.

\section{REFERENCES}

1. Marik PE, Pastores SM, Annane D, et al: American College of Critical Care Medicine. Recommendations for the diagnosis and management of corticosteroid insufficiency in critically ill adult patients: consensus statements from an international task force by the American College of Critical Care Medicine. Crit Care Med 2008; 36(6):1937-1949

2. Nicolaides NC, Kyratzi E, Lamprokostopoulou A, et al: Stress, the stress system and the role of glucocorticoids. Neuroimmunomodulation 2015; 22:6-19

3. Meduri GU, Annane D, Chrousos GP, et al: Activation and regulation of systemic inflammation in ARDS: rationale for prolonged glucocorticoid therapy. Chest 2009; 136:1631-1643

4. Elenkov IJ, lezzoni DG, Daly A, et al: Cytokine dysregulation, inflammation and well-being. Neuroimmunomodulation 2005; 12:255-269

5. Suffredini AF, Fantuzzi G, Badolato R, et al: New insights into the biology of the acute phase response. J Clin Immunol 1999; 19:203-214

6. Friedman R, Hughes AL: Molecular evolution of the NF-kappaB signaling system. Immunogenetics 2002; 53(10-11):964-974

7. Meduri GU, Muthiah MP, Carratu P, et al: Nuclear factor-kappaB- and glucocorticoid receptor alpha- mediated mechanisms in the regulation of systemic and pulmonary inflammation during sepsis and acute respiratory distress syndrome. Evidence for inflammation-induced target tissue resistance to glucocorticoids. Neuroimmunomodulation 2005; 12:321-338

8. Lee SR, Kim HK, Song IS, et al: Glucocorticoids and their receptors: insights into specific roles in mitochondria. Prog Biophys Mol Biol 2013; 112(1-2):44-54

9. Galon J, Franchimont D, Hiroi N, et al: Gene profiling reveals unknown enhancing and suppressive actions of glucocorticoids on immune cells. FASEB J 2002; 16:61-71

10. Li-Tempel T, Larra MF, Sandt E, et al: The cardiovascular and hypothalamus-pituitary-adrenal axis response to stress is controlled by glucocorticoid receptor sequence variants and promoter methylation. Clin Epigenetics 2016; 8:12

11. Midzak A, Papadopoulos V: Adrenal Mitochondria and Steroidogenesis: From Individual Proteins to Functional Protein Assemblies. Front Endocrinol (Lausanne) 2016; 7:106

12. Esteban NV, Loughlin T, Yergey AL, et al: Daily cortisol production rate in man determined by stable isotope dilution/mass spectrometry. J Clin Endocrinol Metab 1991; 72:39-45

13. Vassiliadi DA, Dimopoulou I, Tzanela M, et al: Longitudinal assessment of adrenal function in the early and prolonged phases of critical illness in septic patients: relations to cytokine levels and outcome. $J$ Clin Endocrinol Metab 2014; 99:4471-4480

14. Boonen E, Vervenne $H$, Meersseman $P$, et al: Reduced cortisol metabolism during critical illness. N Engl J Med 2013; 368:1477-1488

15. Boonen E, Meersseman P, Vervenne $\mathrm{H}$, et al: Reduced nocturnal ACTH-driven cortisol secretion during critical illness. Am J Physiol Endocrinol Metab 2014; 306:E883-E892

16. Nenke MA, Rankin W, Chapman MJ, et al: Depletion of high-affinity corticosteroid-binding globulin corresponds to illness severity in sepsis and septic shock; clinical implications. Clin Endocrinol (Oxf) 2015; 82:801-807

17. Beishuizen A, Thijs LG, Vermes I: Patterns of corticosteroid-binding globulin and the free cortisol index during septic shock and multitrauma. Intensive Care Med 2001; 27:1584-1591

18. Tomlinson JW, Moore J, Cooper MS, et al: Regulation of expression of 11 beta-hydroxysteroid dehydrogenase type 1 in adipose tissue: tissuespecific induction by cytokines. Endocrinology 2001; 142:1982-1989

19. Cai TQ, Wong B, Mundt SS, et al: Induction of 11 beta-hydroxysteroid dehydrogenase type 1 but not -2 in human aortic smooth muscle cells by inflammatory stimuli. J Steroid Biochem Mol Bio/ 2001; 77:117-122
20. Hapgood JP, Avenant C, Moliki JM: Glucocorticoid-independent modulation of GR activity: Implications for immunotherapy. Pharmacol Ther 2016; 165:93-113

21. Charmandari E, Nicolaides NC, Chrousos GP: Adrenal insufficiency. Lancet 2014; 383:2152-2167

22. Cain DW, Cidlowski JA: Immune regulation by glucocorticoids. Nat Rev Immuno/ 2017; 17:233-247

23. Goodwin JE, Feng Y, Velazquez H, et al: Endothelial glucocorticoid receptor is required for protection against sepsis. Proc Natl Acad Sci U S A 2013; 110:306-311

24. Goodwin JE, Feng $Y$, Velazquez $\mathrm{H}$, et al: Loss of the endothelial glucocorticoid receptor prevents the therapeutic protection afforded by dexamethasone after LPS. PLoS One 2014; 9:e108126

25. Peeters RP, Hagendorf A, Vanhorebeek I, et al: Tissue mRNA expression of the glucocorticoid receptor and its splice variants in fatal critical illness. Clin Endocrinol (Oxf) 2009; 71:145-153

26. Oakley RH, Cidlowski JA: The biology of the glucocorticoid receptor: new signaling mechanisms in health and disease. J Allergy Clin Immuno/ 2013; 132:1033-1044

27. Boonen E, Bornstein SR, Van den Berghe G: New insights into the controversy of adrenal function during critical illness. Lancet Diabetes Endocrinol 2015; 3:805-815

28. Le Tulzo Y, Pangault C, Amiot L, et al: Monocyte human leukocyte antigen-DR transcriptional downregulation by cortisol during septic shock. Am J Respir Crit Care Med 2004; 169:1144-1151

29. Keh D, Boehnke T, Weber-Cartens S, et al: Immunologic and hemodynamic effects of "low-dose" hydrocortisone in septic shock: a doubleblind, randomized, placebo-controlled, crossover study. Am J Respir Crit Care Med 2003; 167:512-520

30. Arnalich F, Garcia-Palomero E, López J, et al: Predictive value of nuclear factor kappaB activity and plasma cytokine levels in patients with sepsis. Infect Immun 2000; 68:1942-1945

31. Lee YL, Chen W, Chen LY, et al: Systemic and bronchoalveolar cytokines as predictors of in-hospital mortality in severe communityacquired pneumonia. J Crit Care 2010; 25:176.e7-176.13

32. Gomez HG, Gonzalez SM, Londoño JM, et al: Immunological characterization of compensatory anti-inflammatory response syndrome in patients with severe sepsis: a longitudinal study*. Crit Care Med $2014 ; 42: 771-780$

33. Fernandez-Botran R, Uriarte SM, Arnold FW, et al: Contrasting inflammatory responses in severe and non-severe community-acquired pneumonia. Inflammation 2014; 37:1158-1166

34. Kellum JA, Kong L, Fink MP, et al; GenIMS Investigators: Understanding the inflammatory cytokine response in pneumonia and sepsis: results of the Genetic and Inflammatory Markers of Sepsis (GenIMS) Study. Arch Intern Med 2007; 167:1655-1663

35. Meduri GU, Headley S, Kohler G, et al: Persistent elevation of inflammatory cytokines predicts a poor outcome in ARDS. Plasma IL-1 beta and IL-6 levels are consistent and efficient predictors of outcome over time. Chest 1995; 107:1062-1073

36. Meduri GU, Kohler G, Headley S, Tolley E, Stentz F, Postlethwaite A: Inflammatory cytokines in the BAL of patients with ARDS. Persistent elevation over time predicts poor outcome. Chest 1995; 108(5):1303-1314

37. Xiao W, Mindrinos MN, Seok J, et al; Inflammation and Host Response to Injury Large-Scale Collaborative Research Program: A genomic storm in critically injured humans. J Exp Med 2011; 208:2581-2590

38. Aisiku IP, Yamal JM, Doshi P, et al: Plasma cytokines IL-6, IL-8, and $\mathrm{IL}-10$ are associated with the development of acute respiratory distress syndrome in patients with severe traumatic brain injury. Crit Care 2016; 20:288

39. Yende S, D'Angelo G, Kellum JA, et al; GenIMS Investigators: Inflammatory markers at hospital discharge predict subsequent mortality after pneumonia and sepsis. Am J Respir Crit Care Med 2008; 177:1242-1247

40. Dunn AJ: Cytokine activation of the HPA axis. Ann NY Acad Sci 2000; 917:608-617

41. Besedovsky $H$, del Rey A, Sorkin $E$, et al: Immunoregulatory feedback between interleukin-1 and glucocorticoid hormones. Science 1986; 233:652-654 
42. Kanczkowski W, Sue M, Zacharowski K, et al: The role of adrenal gland microenvironment in the HPA axis function and dysfunction during sepsis. Mol Cell Endocrinol 2015; 408:241-248

43. Darling G, Goldstein DS, Stull R, et al: Tumor necrosis factor: immune endocrine interaction. Surgery 1989; 106:1155-1160

44. Mikhaylova IV, Kuulasmaa T, Jääskeläinen J, et al: Tumor necrosis factoralpha regulates steroidogenesis, apoptosis, and cell viability in the human adrenocortical cell line NCl-H295R. Endocrinology 2007; 148:386-392

45. Jäättelä $M$, Carpén $O$, Stenman UH, et al: Regulation of $A C T H$ induced steroidogenesis in human fetal adrenals by rTNF-alpha. Mol Cell Endocrinol 1990; 68:R31-R36

46. Jäättelä $M$, Ilvesmäki V, Voutilainen $R$, et al: Tumor necrosis factor as a potent inhibitor of adrenocorticotropin-induced cortisol production and steroidogenic P450 enzyme gene expression in cultured human fetal adrenal cells. Endocrinology 1991; 128:623-629

47. Engström L, Rosén K, Angel A, et al: Systemic immune challenge activates an intrinsically regulated local inflammatory circuit in the adrenal gland. Endocrinology 2008; 149:1436-1450

48. Bornstein SR, Zacharowski P, Schumann RR, et al: Impaired adrenal stress response in Toll-like receptor 2-deficient mice. Proc Natl Acad Sci U S A 2004; 101:16695-16700

49. Kanczkowski W, Alexaki VI, Tran N, et al: Hypothalamo-pituitary and immune-dependent adrenal regulation during systemic inflammation. Proc Natl Acad Sci U S A 2013; 110:14801-14806

50. Jung $B$, Nougaret $S$, Chanques $G$, et al: The absence of adrenal gland enlargement during septic shock predicts mortality: a computed tomography study of 239 patients. Anesthesiology 2011; 115:334-343

51. Waterhouse R: A case of suprarenal apoplexy. Lancet 1911; 1: 577-578

52. Sharshar T, Annane D, de la Grandmaison GL, et al: The neuropathology of septic shock. Brain Pathol 2004; 14:21-33

53. Mélik Parsadaniantz S, Levin N, Lenoir V, et al: Human interleukin 1 beta: corticotropin releasing factor and ACTH release and gene expression in the male rat: in vivo and in vitro studies. J Neurosci Res $1994 ; 37: 675-682$

54. Parsadaniantz SM, Batsché E, Gegout-Pottie P, et al: Effects of continuous infusion of interleukin 1 beta on corticotropin-releasing hormone (CRH), CRH receptors, proopiomelanocortin gene expression and secretion of corticotropin, beta-endorphin and corticosterone. Neuroendocrinology 1997; 65:53-63

55. Wong ML, Rettori $\mathrm{V}$, al-Shekhlee A, et al: Inducible nitric oxide synthase gene expression in the brain during systemic inflammation. Nat Med 1996; 2:581-584

56. Sharshar T, Gray F, Lorin de la Grandmaison G, et al: Apoptosis of neurons in cardiovascular autonomic centres triggered by inducible nitric oxide synthase after death from septic shock. Lancet 2003; 362:1799-1805

57. Polito A, Sonneville R, Guidoux $\mathrm{C}$, et al: Changes in $\mathrm{CRH}$ and $\mathrm{ACTH}$ synthesis during experimental and human septic shock. PLoS One 2011; 6:e25905

58. McCann SM, Kimura M, Karanth S, et al: The mechanism of action of cytokines to control the release of hypothalamic and pituitary hormones in infection. Ann N Y Acad Sci 2000; 917:4-18

59. Boonen $\mathrm{E}$, Langouche L, Janssens $\mathrm{T}$, et al: Impact of duration of critical illness on the adrenal glands of human intensive care patients. J Clin Endocrinol Metab 2014; 99:1569-1582

60. Bornstein SR: Predisposing factors for adrenal insufficiency. N Engl J Med 2009; 360:2328-2339

61. Vuong C, Van Uum SH, O'Dell LE, et al: The effects of opioids and opioid analogs on animal and human endocrine systems. Endocr Rev 2010; 31:98-132

62. Henzen C, Suter A, Lerch E, et al: Suppression and recovery of adrenal response after short-term, high-dose glucocorticoid treatment. Lancet 2000; 355:542-545

63. Cortés-Puch I, Hicks CW, Sun J, et al: Hypothalamic-pituitary-adrenal axis in lethal canine Staphylococcus aureus pneumonia. Am J Physiol Endocrinol Metab 2014; 307:E994-E1008

64. Annane D, Maxime V, Ibrahim F, et al: Diagnosis of adrenal insufficiency in severe sepsis and septic shock. Am J Respir Crit Care Med $2006 ; 174: 1319-1326$
65. Vermes I, Beishuizen A, Hampsink RM, et al: Dissociation of plasma adrenocorticotropin and cortisol levels in critically ill patients: possible role of endothelin and atrial natriuretic hormone. $J$ Clin Endocrinol Metab 1995; 80:1238-1242

66. Polito A, Lorin de la Grandmaison G, Mansart A, et al: Human and experimental septic shock are characterized by depletion of lipid droplets in the adrenals. Intensive Care Med 2010; 36:1852-1858

67. Buss NA, Gavins FN, Cover PO, et al: Targeting the annexin 1-formyl peptide receptor 2/ALX pathway affords protection against bacterial LPS-induced pathologic changes in the murine adrenal cortex. FASEB J 2015; 29:2930-2942

68. Wang N, Weng W, Breslow JL, et al: Scavenger receptor BI (SR-BI) is up-regulated in adrenal gland in apolipoprotein A-I and hepatic lipase knock-out mice as a response to depletion of cholesterol stores. In vivo evidence that SR-BI is a functional high density lipoprotein receptor under feedback control. J Biol Chem 1996; 271:21001-21004

69. Cai L, Ji A, de Beer FC, et al: SR-BI protects against endotoxemia in mice through its roles in glucocorticoid production and hepatic clearance. J Clin Invest 2008; 118:364-375

70. Gilibert S, Galle-Treger L, Moreau M, et al: Adrenocortical scavenger receptor class B type I deficiency exacerbates endotoxic shock and precipitates sepsis-induced mortality in mice. J Immuno/ 2014; 193(2):817-826

71. Bruder EA, Ball IM, Ridi S, et al: Single induction dose of etomidate versus other induction agents for endotracheal intubation in critically ill patients. Cochrane Database Syst Rev 2015; 1:CD010225

72. Daniell HW: Opioid contribution to decreased cortisol levels in critical care patients. Arch Surg 2008; 143:1147-1148

73. Thomson I, Fraser R, Kenyon CJ: Regulation of adrenocortical steroidogenesis by benzodiazepines. J Steroid Biochem Mol Biol 1995; 53:75-79

74. Tominaga T, Fukata J, Naito $Y$, et al: Effects of corticostatin-I on rat adrenal cells in vitro. J Endocrinol 1990; 125:287-292

75. Dendoncker K, Libert C: Glucocorticoid resistance as a major drive in sepsis pathology. Cytokine Growth Factor Rev 2017; 35:85-96

76. Marik PE: Critical illness-related corticosteroid insufficiency. Chest 2009; 135:181-193

77. Bergquist $M$, Nurkkala M, Rylander $C$, et al: Expression of the glucocorticoid receptor is decreased in experimental Staphylococcus aureus sepsis. J Infect 2013; 67:574-583

78. Bergquist M, Lindholm C, Strinnholm M, et al: Impairment of neutrophilic glucocorticoid receptor function in patients treated with steroids for septic shock. Intensive Care Med Exp 2015; 3:59

79. Vardas K, llia S, Sertedaki A, et al: Increased glucocorticoid receptor expression in sepsis is related to heat shock proteins, cytokines, and cortisol and is associated with increased mortality. Intensive Care Med Exp 2017; 5:10

80. Guerrero J, Gatica HA, Rodríguez M, et al: Septic serum induces glucocorticoid resistance and modifies the expression of glucocorticoid isoforms receptors: a prospective cohort study and in vitro experimental assay. Crit Care 2013; 17:R107

81. Meduri GU, Tolley EA, Chrousos GP, et al: Prolonged methylprednisolone treatment suppresses systemic inflammation in patients with unresolving acute respiratory distress syndrome: evidence for inadequate endogenous glucocorticoid secretion and inflammationinduced immune cell resistance to glucocorticoids. Am J Respir Crit Care Med 2002; 165:983-991

82. van den Akker EL, Koper JW, Joosten K, et al: Glucocorticoid receptor mRNA levels are selectively decreased in neutrophils of children with sepsis. Intensive Care Med 2009; 35:1247-1254

83. Ledderose C, Möhnle P, Limbeck E, et al: Corticosteroid resistance in sepsis is influenced by microRNA-124-induced downregulation of glucocorticoid receptor- $\alpha$. Crit Care Med 2012; 40:2745-2753

84. Kamiyama K, Matsuda N, Yamamoto S, et al: Modulation of glucocorticoid receptor expression, inflammation, and cell apoptosis in septic guinea pig lungs using methylprednisolone. Am J Physiol Lung Cell Mol Physiol 2008; 295:L998-L1006

85. Cohen J, Pretorius CJ, Ungerer JP, et al: Glucocorticoid Sensitivity Is Highly Variable in Critically III Patients With Septic Shock and Is Associated With Disease Severity. Crit Care Med 2016; 44:1034-1041 